\title{
Formation of Manganese Dioxide Coating with Catalytic Activity on Thick Boehmite Film by Hydrothermal Method
}

\author{
Takayoshi Fujino, Shinichi Yamaguchi* and Takanori Hattori* \\ Department of Applied Chemistry, Faculty of Science \& Technology, Kinki University, Higashiosaka 577-8502, Japan
}

Aluminum has excellent workability and surface finishing, but it corrodes easily and has low hardness. Therefore, in this study, an excellent high corrosion resistance oxide film was prepared by hydrothermal treatment on aluminum in the primary treatment. In the secondary treatment, $\mathrm{MnO}_{2}$ was immobilized on high corrosion resistance oxide film by hydrothermal treatment.

Aluminum was treated by hydrothermal treatment for 30 min under $483 \mathrm{~K}(2.0 \mathrm{MPa})$ conditions in a $0.04 \mathrm{kmol} / \mathrm{m}^{3}$ aluminum nitrate aqueous solution. Adding aluminum nitrate to prepared thick boehmite film $(20 \mu \mathrm{m})$ by formed globules in the primary treatment, and it possessed a wide surface area. The primary processing film was treated for 30 min under $453-483 \mathrm{~K}$ (1.0-2.0 MPa) conditions in a potassium permanganate aqueous solution by hydrothermal treatment, and nanoorder $\mathrm{MnO}_{2}(30 \mathrm{~nm})$ was immobilized onto the boehmite film. $\mathrm{MnO}{ }_{2}-$ boehmite film with wide surface area and high oxidation activity was prepared.

(Received August 8, 2005; Accepted October 21, 2005; Published December 15, 2005)

Keywords: thick boehmite film, manganese dioxide, hydrothermal method, aluminum, oxidation catalytic activity

\section{Introduction}

Aluminum has excellent workability and surface finishing, but it is corrodes easily and has low hardness. Therefore, anodic oxidation, ${ }^{1,2)}$ chemical conversion treatment, ${ }^{3-7)}$ and plating ${ }^{8)}$ are studied for various surface finishing, to improve the hardness and corrosion resistance. But since the main ingredient of the film prepared by these methods is amorphous, we don't expect high corrosion resistance under acid, alkaline, or such severe conditions as high temperature and pressure. It has been reported that boehmite film prepared by a hydrothermal method has high hardness and corrosion resistance. ${ }^{9)}$ Boehmite prepared film by this method form globular the crystals. High catalytic activity was expected because catalyst is immobilized on the boehmite film with wide surface area. Manganese dioxide was used to remove the dioxin, ${ }^{10)}$ carbon monoxide, chloric gas, sulfur dioxide, ozonic gas, and other fetid gases because it remarkably decomposes the hydrogen peroxide and consumes the oxygen. But handling is difficult because it's a powder. In this study, manganese dioxide was immobilized on boehmite film, and aluminum nitrate was added as an extending film agent. Preparation of a thick boehmite was carried out as the primary treatment. Potassium permanganate was added in the secondary treatment, and then manganese dioxide was immobilized on the boehmite film by hydrothermal treatment, and the preparation of a functionality film was attempted. The boehmite and the manganese dioxide were analyzed using thin film X-ray diffractometry and a scanning electron microscope. The catalytic activity of the prepared film was analyzed by decomposition of $\mathrm{H}_{2} \mathrm{O}_{2}$.

\section{Experimental}

\subsection{Preparation of the primary tretment film by hydro- thermal method}

An aluminum plate (purity; 99.85\%) and an aluminum mesh (purity: $99.5 \%, \phi: 0.8 \mathrm{~mm}$, porosity: $43 \%$ ) were pre-

*Graduate Student, Kinki University viously treated in advance with surface-active agent for $5 \mathrm{~min}$ at $323 \mathrm{~K}$, and then crystalline film was prepared by the portable reactor in a $0.04 \mathrm{kmol} \cdot \mathrm{m}^{-3}$ aluminum nitrate aqueous solution. It was heated by a band-shaped electric heater, and the solution temperature was set at $483 \mathrm{~K}$ $(2.0 \mathrm{MPa})$. Hold time was set as $30 \mathrm{~min}$ after reaching the processing temperature, and then the prepared film was treated by ultrasonic cleaning. Film thickness was measured by a eddy-current film thickness measuring machine.

\subsection{Preparation of functionality film with catalytic activity}

Functionality film was prepared by portable reactor in $50 \mathrm{~mL} 0.01-0.1 \mathrm{kmol} \cdot \mathrm{m}^{-3}$ potassium permanganate aqueous solution. It was heated by electric heater, and the solution temperature was set at 453-483 K (1.0-2.0 MPa). Hold time was set for $30 \mathrm{~min}$ after it reached the processing temperature, and then the prepared film was treated by ultrasonic cleaning.

\subsection{Surface and cross-sectional observation of film}

The prepared film was covered with a $0.02 \mu \mathrm{m}$ thick layer of Pt-Pd by vapor deposition equipment. The acceleration voltage was set at $15 \mathrm{kV}$, and the surface and a cross section were observed by scanning electron microscope (SEM) to observe the organization of the film and its structure.

\subsection{Characterization of prepared films}

Film structure was analyzed by thin film X-ray diffraction using a $\mathrm{CuK} \alpha$ ray under beam conditions of $40 \mathrm{kV}$ and $80 \mathrm{~mA}$. The form of manganese on the prepared film was analyzed by an X-ray photoelectron spectroscope (XPS) under the beam conditions of $8 \mathrm{kV}$ and $30 \mathrm{~mA}$.

\subsection{Quantitative analysis of manganese}

Quantitative analysis of manganese was carried out by inductively coupled plasma (ICP) emission spectrometry. The samples were dissolved in hydrochloric acid, and then the solution was analyzed. 


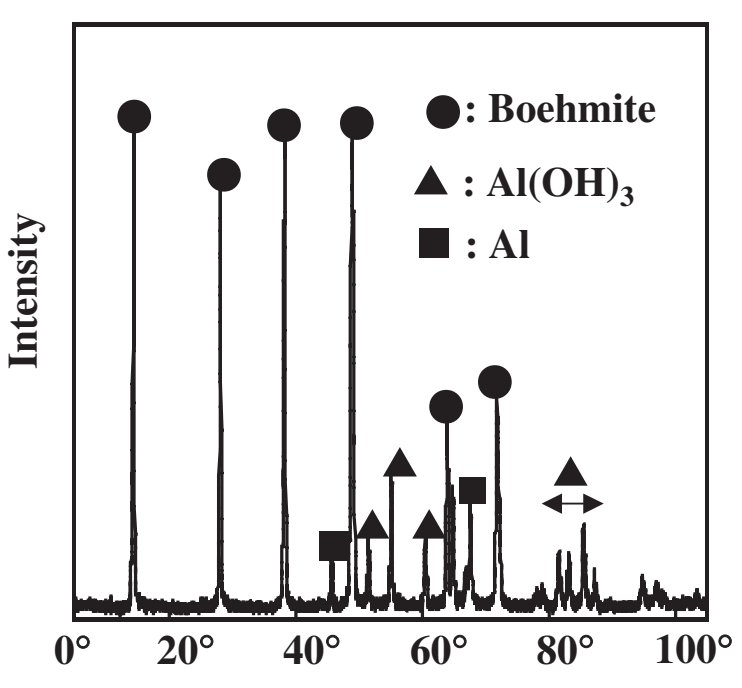

Diffraction angle, $2 \theta$

Fig. 1 X-ray diffraction pattern of prepared film by hydrothermal treatment.

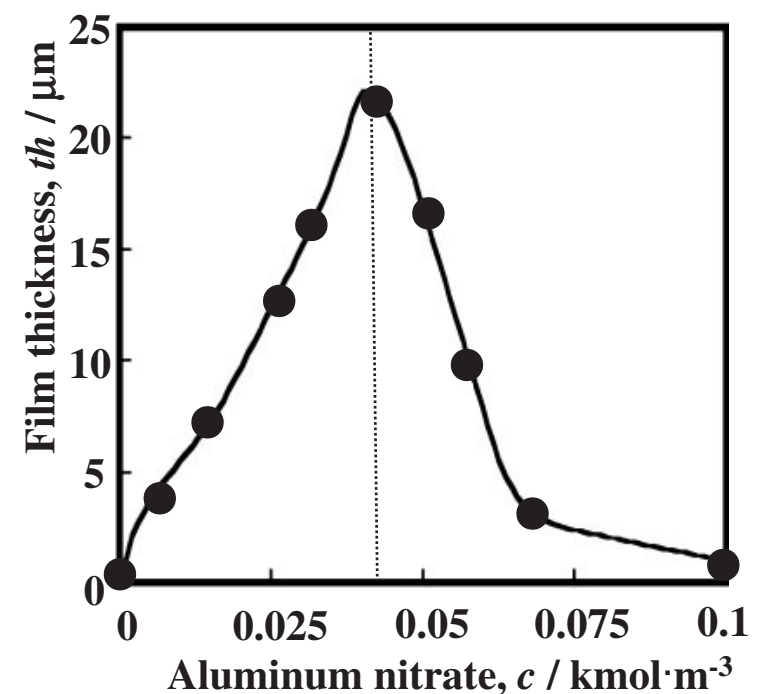

Fig. 2 Relationships between film thickness and the amount of addition of aluminum nitrate by hydrothermal treatment.

\subsection{Catalytic activity}

The oxidation catalytic activity of the prepared film was estimated by a hydrogen peroxide solution decomposition reaction.

Testing condition

Test piece: $20 \times 20 \mathrm{~mm} ; \mathrm{H}_{2} \mathrm{O}_{2}$ initial concentration: 0.05 $\mathrm{kmol} \cdot \mathrm{m}^{-3}$;

Total volume: $200 \mathrm{~cm}^{3}$; temperature: $297 \mathrm{~K}$

\section{Results and Discussion}

\subsection{Boehmite film}

\subsubsection{X-ray diffraction pattern}

The prepared film by hydrothermal treatment in the primary treatment was white. Figure 1 shows the XRD results of the prepared film; the prepared film was boehmite from the result of XRD. The peaks that didn't depend on

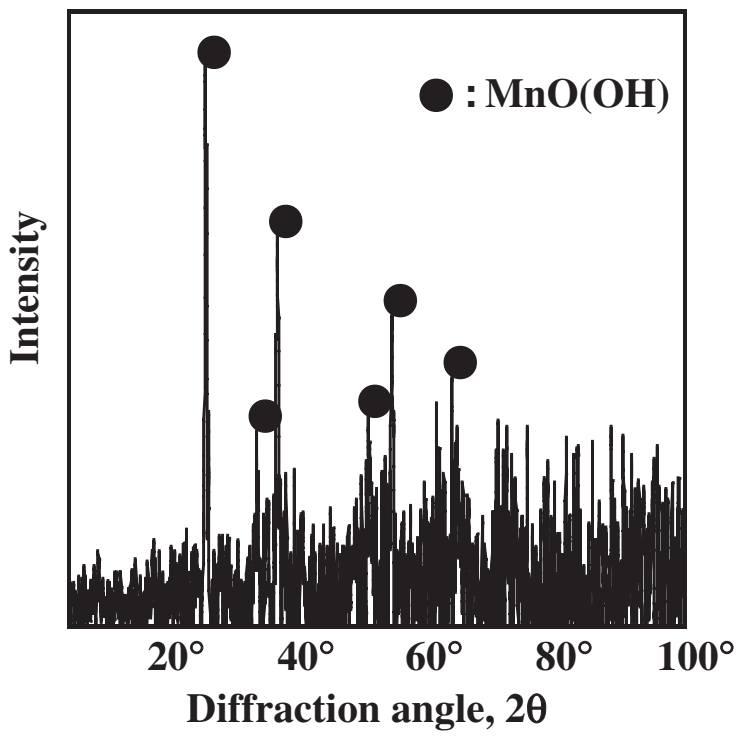

Fig. 3 X-ray diffraction pattern of prepared film.

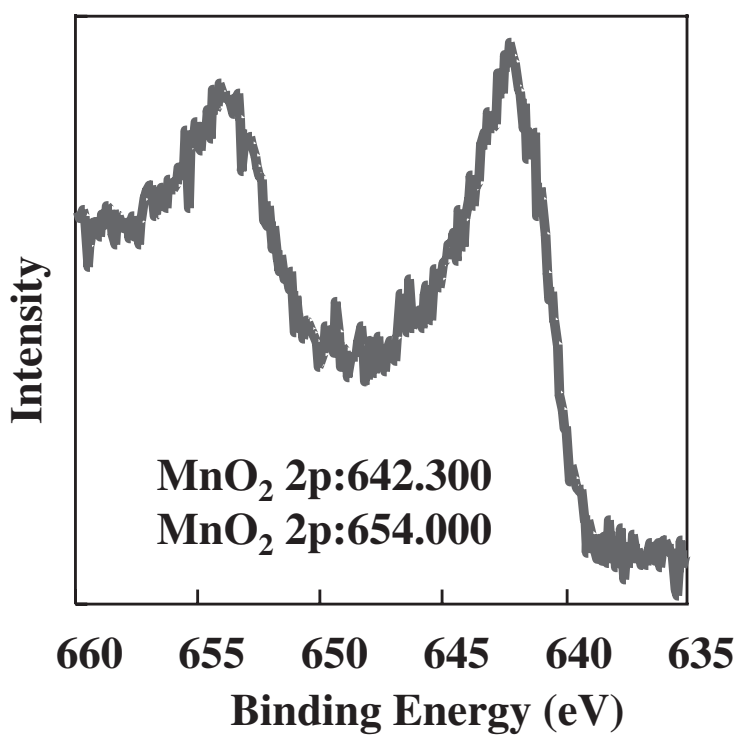

Fig. 4 XP spectra of $\mathrm{MnO}_{2}$ electron binding energy of the functional boehmite films.

boehmite were attributed to aluminum hydroxide and metal aluminum.

\subsubsection{Increase thickness of boehmite film by aluminum nitrate}

Figure 2 shows the relationship between film thickness and aluminum nitrate concentration. The thickness of the boehmite film increased in proportion to the concentration of aluminum nitrate. However, the aluminum nitrate wasn't directly affected by this reaction. Aluminum ions increased by an aluminum nitrate, so deposition of boehmite increased But the film thickness decreased when more than $0.04 \mathrm{kmol}$. $\mathrm{m}^{-3}$ aluminum nitrate was added. Deposition of boehmite on the aluminum is restrained because the $\mathrm{pH}$ of the solution shift to acid by nitrate ion $(\mathrm{pH} \mathrm{3.8} \rightarrow \mathrm{pH} 2.3)$ and the dissolution of aluminum was intensel, decreasing the production of the films. 


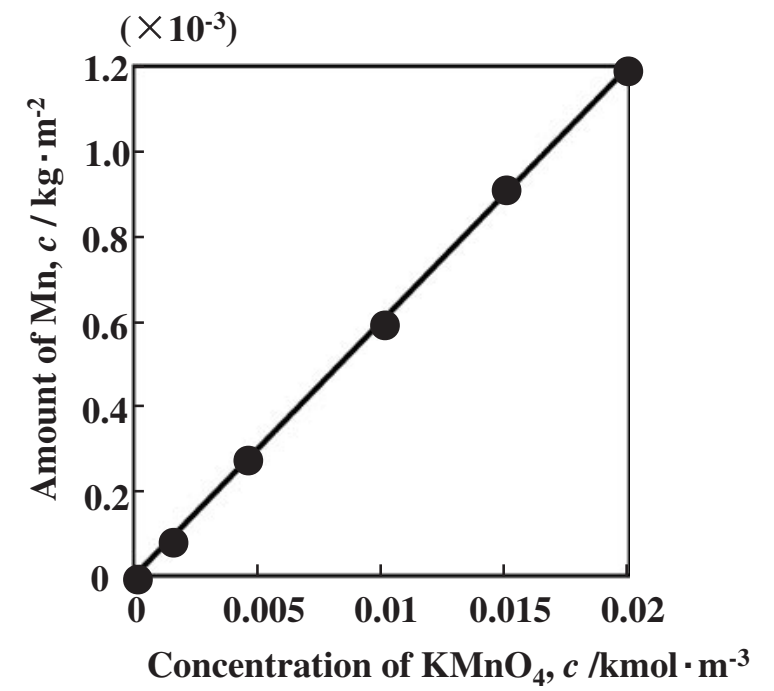

Fig. 5 Relationships between amount of the addition of manganese oxides and containing quantity of $\mathrm{Mn}$ in $\mathrm{MnO}_{2}$-boehmite film.

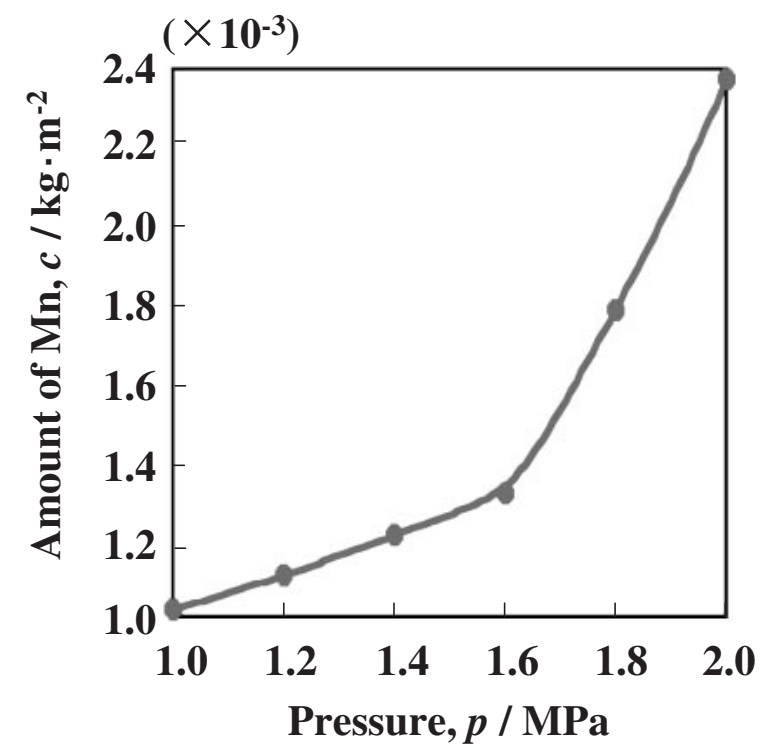

Fig. 6 Relationships between amount of steam pressure and contaning quantity of $\mathrm{Mn}$ in $\mathrm{MnO}_{2}$-boehmite film.

\subsection{Functionality film with catalytic activity}

\subsubsection{Characterization of $\mathrm{MnO}_{2}$-boehmite film}

Figure 3 shows the XRD patterns of the prepared film in potassium permanganate by hydrothermal method. Figure 4 shows the XPS results of the film. It was confirmed that the film was contained manganite $[\mathrm{MnO}(\mathrm{OH})]$ and manganese dioxide by the of X-ray diffraction and XPS results, ${ }^{11)}$ which show the composite film of the crystalline manganite and the amorphous manganese dioxide.

\subsubsection{Amount of manganese in $\mathrm{MnO}_{2}$-boehmite film}

Figure 5 shows the relationship between the immobilized amount of the manganese and the concentration of potassium permanganate. The amount of manganese increased in proportional to the potassium permanganate concentration. Figure 6 shows the relationship between pressure (temper-

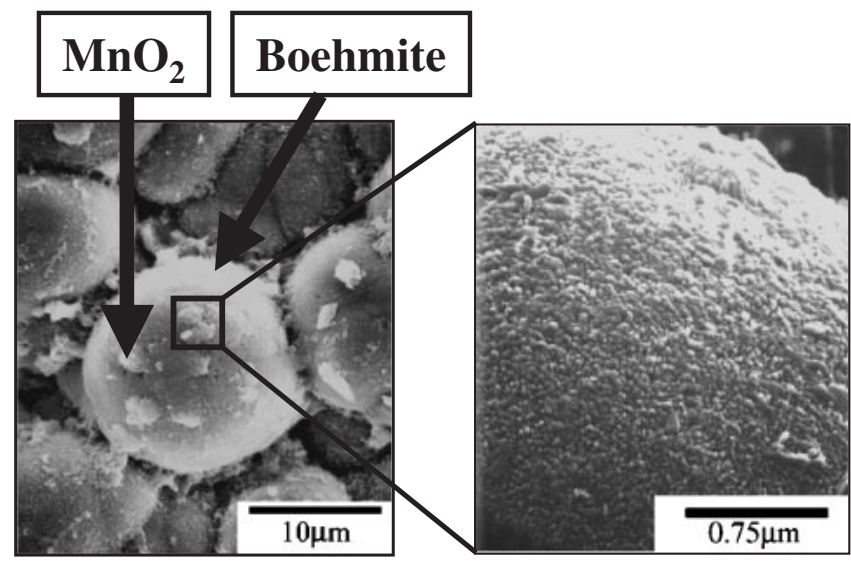

\section{$\mathrm{MnO}_{2}$-boehmite film}

Fig. 7 Scanning electron micrographs of surface of the functional boehmite films.

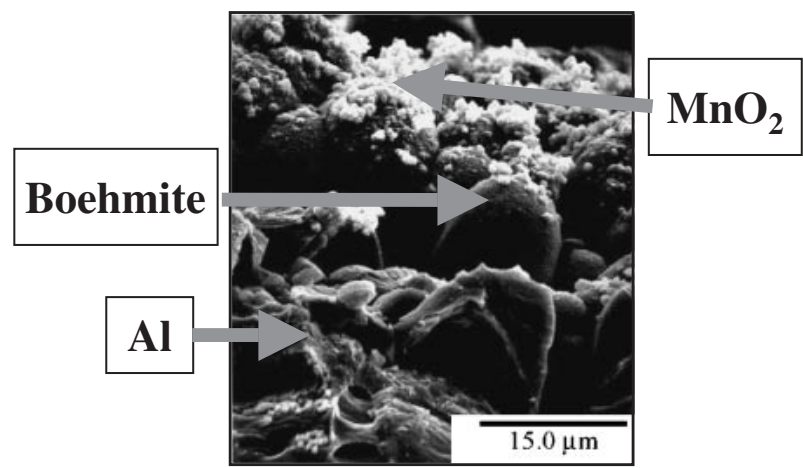

Fig. 8 Scanning electron micrographs of cross-section of the functional boehmite films.

ature) and the amount of manganese in secondary treatment. The immobilized amount of $\mathrm{MnO}_{2}$ increased with temperature because a hydrolysis reaction was promoted with a rise of temperature.

\subsubsection{Surface and cross-section images of $\mathrm{MnO}_{2}$-boehm- ite film}

Figure 7 shows the surface image of $\mathrm{MnO}_{2}$-boehmite film. Nanoorder manganese dioxide immobilized onto the globular boehmite film. Figure 8 shows a cross-section image. The manganese dioxide covered the entire whole surface of the globular thick boehmite film. Functionality boehmite film has wide surface area and high adhesibility. The prepared film was expected to have high catalytic activity.

\subsection{Catalytic activity of functionality film}

Figure 9 shows the oxidation catalytic activity of the $\mathrm{MnO}_{2}$-boehmite film by decomposition of hydrogen peroxide. Manganese dioxide functioned as a catalyst, and oxygen was formed conspicuously. As a result, the initial rate was $0.008 \mathrm{~mol} \cdot \mathrm{h}^{-1}$, and the average decomposition rate was $0.004 \mathrm{~mol} \cdot \mathrm{h}^{-1}$. The prepared film by hydrothermal treatment had higher catalyst activity than the film by manganese nitrate. ${ }^{12)}$ The prepared film by hydrothermal treatment was 


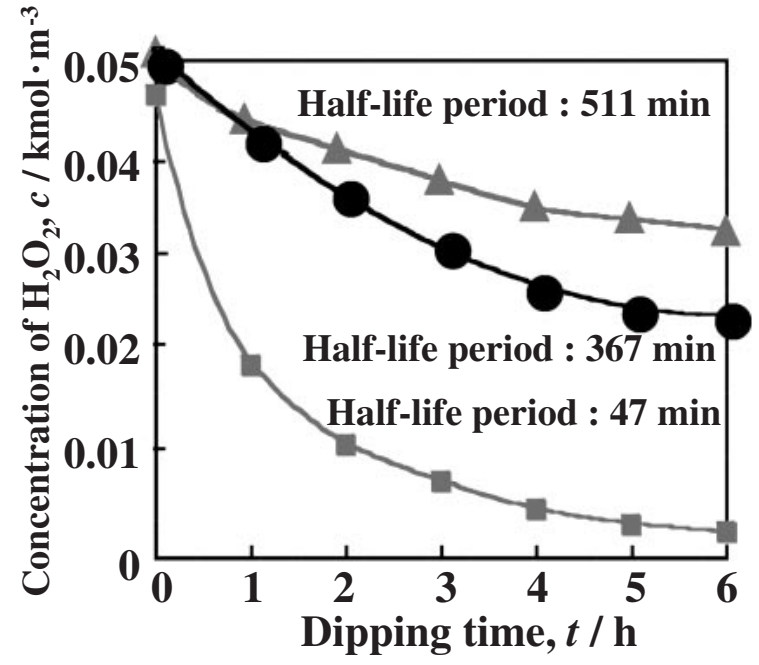

Fig. 9 Relationships between concentration of $\mathrm{H}_{2} \mathrm{O}_{2}$ and dipping time of $\mathrm{MnO}_{2}$-boehmite film $\boldsymbol{\Delta}: \mathrm{MnO}_{2}$ by $\mathrm{Mn}\left(\mathrm{NO}_{3}\right)_{2} \bigcirc$ : The prepared film 口: The prepared film (mesh).

nanoorder manganese dioxide with a wide surface area. Therefore, the prepared film had high oxidation catalytic activity. When the shape of the aluminum was mesh, catalytic activity was higher than the plate. The mesh surface area is about 1.8 times as wide as the plate. However, the catalytic activity of prepared film on the mesh was 10 times as high as the plate. The decomposition reaction was efficient because the substrate passed through a mesh. The aluminum has excellent workability. Aluminum can be worked into various shapes such as a honeycomb sandwich structure. Therefore, catalytic activity improvements are expected.

\subsection{Forming process of $\mathrm{MnO}_{2}$-boehmite film}

Figure 10 shows the formation process of $\mathrm{MnO}_{2}$-boehmite film. Aluminum reacted only to water in the primary treatment. Aluminum was dissolved to heat the solution and then deposited as boehmite to cool, as shown in formula (a), (b). Potassium permanganate was reduced in the secondary treatment, and deposited as manganese dioxide and manganite. The $\mathrm{pH}$ of the solution changed from 5.3 to 7.6 by this reaction. The reaction mechanism is shown in formula (c).

Therefore, the amount of immobilized manganese increased with temperature. The potassium permanganate is reduced by aluminum and deposited as manganese dioxide, as shown in formula $(c)^{\prime}$.

\section{Conclusion}

Thick boehmite film was prepared in an aluminum nitrate aqueous solution by hydrothermal treatment in the primary treatment. $\mathrm{MnO}_{2}$-boehmite film was prepared in a potassium permanganate aqueous solution by hydrothermal treatment in the secondary treatment.

(1) The prepared boehmite film $(20 \mu \mathrm{m})$ by hydrothermal treatment became globular and possessed a wide

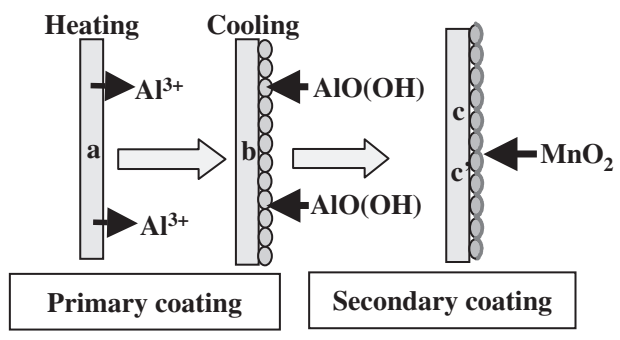

a) $\mathrm{Al}+3 \mathrm{H}_{2} \mathrm{O} \rightarrow \mathrm{Al}^{3+}+3 \mathrm{OH}^{-}+3 / 2 \mathrm{H}_{2}$

b) $\mathrm{Al}^{3+}+3 \mathrm{OH}^{-} \rightarrow \mathrm{AlO}(\mathrm{OH})+\mathrm{H}_{2} \mathrm{O}$

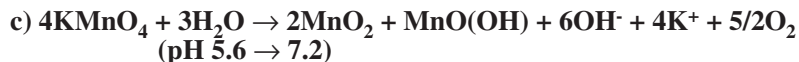

c') $\mathrm{KMnO}_{4}+\mathrm{Al} \rightarrow \mathrm{MnO}_{2}+\mathrm{Al}^{3+}+\mathrm{K}^{+}+\mathrm{O}_{2}$

Fig. 10 Forming process of the chemical conversion coatings.

surface area.

(2) The thick boehmite film was prepared by adding aluminum nitrate.

(3) Nanoorder $\mathrm{MnO}_{2}$ was immobilized onto boehmite film in a potassium permanganate aqueous solution by hydrothermal treatment.

(4) The prepared film had higher catalyst activity than the film by manganese nitrate.

(5) When the shape of the substrate was mesh, catalytic activity was higher than the plate.

\section{Acknowledgements}

This work was "University-Industry Joint Research" project for Private Universities and supported by funding from the Ministry of Education, Culture, Sports, Science and Technology private school grant, 2002-2006. The authors thank them for their immense assistance in the development of functional chemical conversion coatings and its applicability.

\section{REFERENCES}

1) T. Fujino, K. Okumura and H. Noguchi: Keikinzoku 41 (1990) 417.

2) Y. Fukuda and T. Fukushima: Bull. Chem. Soc. Jpn. 53 (1985) 202.

3) H. J. Wittrock: Metal Finishing 71 (1996) 50.

4) T. Uchiyama and T. Abe: Keikinzoku 32 (1982) 202.

5) T. Fujino, M. Miyamoto and H. Noguchi: Keikinzoku 50 (2000) 486490.

6) T. Fujino, M.Yogoro and H. Noguchi: Keikinzoku 47 (1997) 533-538.

7) H. Noguchi, M. Shimomura and T. Yoshimura: Hyoumengijutu 48 (1997) 76-81.

8) M. Obradovic, J. Stevanovic and A. Despic: J. Electro. Chem. 491 (2000) 188-196.

9) T. Fujino, M. Shimokado and H. Noguchi: Keikinzoku 52 (2002) 442447.

10) R. Yamada: Handbook of Environmental catalyst, (2001) 105, NTS Co. Ltd.

11) N. Ikeo, Y. Iijima, N. Niimura, M. Sigematsu, T. Tazawa, S. Matsumoto, K. Kojima and Y. Nagasawa: Handbook of X-ray Photoelectron Spectroscopy, (JEOL, Tokyo, 1991), p. 74.

12) Patent No. 2003-311126. 